\title{
The case for expanding the definition of 'key populations' to include high-risk groups in the general population to improve targeted HIV prevention efforts
}

\author{
O Shisana, ${ }^{1,2}$ BA, MA, ScD; N Zungu, ${ }^{1}$ BA, BA Hons, MA, DPhil; M Evans, ${ }^{1}$ BMus, MA; K Risher, ${ }^{3}$ BA, MHS; T Rehle, ${ }^{1,4}$ MD, MPH, PhD; \\ D Celentano, ${ }^{3} \mathrm{MHS}, \mathrm{ScD}$ \\ ${ }^{1}$ Human Sciences Research Council, Cape Town, South Africa \\ ${ }^{2}$ Department of Psychiatry and Mental Health, Faculty of Health Sciences, University of Cape Town, South Africa \\ ${ }^{3}$ Johns Hopkins Bloomberg School of Public Health, Baltimore, MD, USA \\ ${ }^{4}$ School of Public Health and Family Medicine, Faculty of Health Sciences, University of Cape Town, South Africa
}

Corresponding author: O Shisana (oshisana@hsrc.ac.za)

\begin{abstract}
Background. Two additional key populations within the general population in South Africa (SA) that are at risk of HIV infection are black African women aged 20 - 34 years and black African men aged 25 - 49 years.

Objective. To investigate the social determinants of HIV serostatus for these two high-risk populations.

Methods. Data from the 2012 South African National HIV Prevalence, Incidence, and Behaviour Survey were analysed for black African women aged 20 - 34 years and black African men aged 25 - 49 years.

Results. Of the 6.4 million people living with HIV in SA in 2012, 1.8 million (28\%) were black women aged 20 - 34 years and 1.9 million (30\%) black men aged 25 - 49 years. In 2012, they constituted 58\% of the total HIV-positive population and $48 \%$ of the newly infected population. Low socioeconomic status (SES) was strongly associated $(p<0.001)$ with being HIV-positive among black women aged $20-34$ years, and was marginally significant among black men aged 25 - 49 years $(p<0.1)$.

Conclusion. Low SES is a critical social determinant for HIV infection among the high-risk groups of black African women aged 20 34 years and black African men aged 25 - 49 years. Targeted interventions for these key populations should prioritise socioeconomic empowerment, access to formal housing and services, access to higher education, and broad economic transformation.
\end{abstract}

S Afr Med J 2015;105(8):664-669. DOI:10.7196/SAMJnew.7918

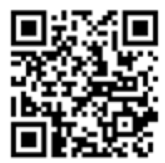

South Africa (SA) has an HIV epidemic that is driven by heterosexual transmission and characterised by dynamic risk groups and profiles. ${ }^{[1,2]}$ Key populations refers to groups that are at high risk of HIV infection, stigmatised by society because of their identities or behaviours, and less likely than other groups to be reached by interventions; ${ }^{[2]}$ traditionally, these include men who have sex with men (MSM), sex workers, people who inject drugs ${ }^{[3]}$ and transgender persons. ${ }^{[4]}$ These traditional key populations have been important for understanding HIV in industrialised countries with low-level or concentrated epidemics, and in recent years it has been determined that traditional key populations represent a major portion of the global epidemic. In reviewing the national response to HIV/AIDS, SA has identified traditional key populations such as MSM as critical to reach with interventions, owing to the high HIV prevalence in this group. ${ }^{[5]}$ The current National Strategic Plan on HIV, STIs and TB (2012 - 2016) now includes MSM and recommends a more targeted approach to reducing infections in this group.

While focusing on traditional key populations, it is important to recognise that within the general population there are groups that are vulnerable and at particular risk of being infected with HIV, particularly in the unique context that is SA. ${ }^{[1-3]}$ With a generalised epidemic, large segments of the general population rather than traditional key populations are likely to be driving the epidemic. These larger subpopulations can be identified through national surveys, whereas traditional key populations are smaller, often hard-to-reach groups that can be studied through sampling approaches such as respondent-driven sampling. The reasons for the vulnerability among groups within the general population vary, and may include factors such as occupation, living arrangements, personal behaviour and behaviour of partners. Groups that have been suggested as additional key populations are migrant populations (the migrants themselves and their partners), truckers, prisoners, soldiers, internally displaced people, refugees, and orphans and vulnerable children. ${ }^{[3]}$ There is therefore a need to expand the definition of key populations and not limit it to distinct traditional groups. ${ }^{[1-3]}$ Shisana et al., ${ }^{[1]}$ for example, define key populations as groups that have a higher HIV prevalence than the general population. This is in line with the UNAIDS definition, which puts more emphasis on 'communities most likely to be living with HIV or those disproportionately affected by it when compared with the general population. ${ }^{[6]}$ The definition of key populations therefore depends on the epidemiological profile of the country and the social dynamics that operate in relation to HIV infections in that country, and in SA, the definition of key populations at risk of HIV should be tailored to the local context.

In hyperendemic countries, typically economically constrained low- and middle-income countries, groups that do not fall within the traditional definition of key populations are often not the focus of targeted HIV prevention interventions. The challenge is that these large subpopulations are part of the general population and not easily distinguishable by a unifying social criterion. Such large population groups are likely to be heterogeneous and hence difficult to target for specific interventions. However, it is necessary to identify both these groups and their social determinants, because the general HIV prevalence in a country is unlikely to be reduced unless these high- 
risk groups are targeted with appropriate interventions that meet specific risks and needs.

Human Sciences Research Council researchers ${ }^{[1,2]}$ have identified key populations within the general population to include, inter alia, black African women aged 20 - 34 years and black African men aged 25 - 49 years, among whom the prevalence of HIV infection in 2012 was found to be $31.6 \%$ and $25.7 \%$, respectively. ${ }^{[2]}$ The $\mathrm{HIV}$ incidence estimates based on assays (\% per year) was also found to be high at $4.54 \%$ and $1.84 \%$, respectively, in these same populations. ${ }^{[2]}$ Although there is a breadth of research in SA focusing on HIV and women more generally, little is known about the social factors that shape the risk profiles of these key populations, particularly in respect of their demographic information, including employment, residence and socioeconomic status (SES).

\section{Methods}

The data used in this study are part of a larger population-based survey conducted in SA in 2012 using a multistage stratified survey design. The detailed methodology of the study is described elsewhere. ${ }^{[2]}$ In short, a probability sample of 15 households was drawn from each of the randomly selected 1000 enumeration areas (EAs). The selection of EAs was stratified by province and locality type, defined as urban formal, urban informal, rural formal (including commercial farms), and rural informal localities. All household members were invited to participate in the 2012 survey.

Dried blood spot specimens for HIV testing were collected from consenting participants. A detailed questionnaire soliciting information related to demographic characteristics, knowledge, attitudes, practices and behaviours was administered. Participants were guaranteed anonymity, and all questionnaires and blood samples were linked using a unique bar code. This article is based on a subsample of unweighted adult data, and the analysis focused on black adults aged 20 - 49 years who participated in the survey. Separate analyses of black women aged 20 - 34 years and black men aged 25 49 years were conducted in order to assess the associations between social factors and HIV status in key populations.

The survey protocol was approved by the HSRC's Research Ethics Committee (REC: $5 / 17 / 11 / 10)$, as well as by the Associate Director of Science of the National Center for HIV and AIDS, Viral Hepatitis, STD and
TB Prevention at the US Centers for Disease Control and Prevention (CDC).

An SES scale was developed using 13 items from the questionnaire related to possession of and/or access to toilet facilities; cooking energy; access to electricity, radio, television, telephone, cell phone (mobile phone), refrigerator, personal computer and washing machine; number of rooms in the dwelling; extent to which the household has sufficient money; and drinking water source. Each item ranged from 1 to 4 , and the scale ranged from 13 to 52. Reliability of the SES scale was assessed using Cronbach's alpha (Table 1).

Bivariate analyses and multiple logistic regression analyses were conducted to assess the relationship between SES and HIV status, stratified by gender. The SES scale was treated as a continuous variable in the regression analyses.

\section{Results}

Of the 6.4 million people living with HIV in SA in 2012, 1.8 million were black women aged $20-34$ years and 1.9 million were black men aged 25 - 49 years. In total, they constituted $58 \%$ of the HIV-positive population and $48 \%$ of the newly infected population in 2012 (percentages recalculated from the earlier study $\left.{ }^{[2]}\right)$.

Table 2 presents demographic characteristics of the sample by gender. Among black men aged 25 - 49 years, the greatest proportion $(30.3 \%)$ of respondents were 25 - 29 years old, lived in urban formal areas $(41.6 \%)$, and were employed full-time (42.4\%), although a large proportion (30.7\%)

\section{Table 1. Items and scoring of the SES scale}

\begin{tabular}{|c|c|c|}
\hline \multirow{2}{*}{$\begin{array}{l}\text { Item } \\
\text { Toilet facilities }\end{array}$} & \multicolumn{2}{|c|}{ Scores } \\
\hline & 4 & Flush toilet (own or shared) \\
\hline & 3 & Pit latrine with ventilation \\
\hline & 2 & Pit latrine without ventilation or bucket \\
\hline & 1 & No facility/other \\
\hline \multirow[t]{4}{*}{ Cooking fuel } & 4 & Electricity or gas \\
\hline & 3 & Coal \\
\hline & 2 & Paraffin (kerosene) \\
\hline & 1 & Wood, dung, or other \\
\hline \multirow[t]{8}{*}{ Household access to } & $4 / 1$ & Electricity (yes/no) \\
\hline & $4 / 1$ & Radio (yes/no) \\
\hline & $4 / 1$ & Television (yes/no) \\
\hline & $4 / 1$ & Landline (yes/no) \\
\hline & $4 / 1$ & Cellphone (yes/no) \\
\hline & $4 / 1$ & Refrigerator (yes/no) \\
\hline & $4 / 1$ & Personal computer (yes/ no) \\
\hline & $4 / 1$ & Washing machine (yes/no) \\
\hline \multirow[t]{4}{*}{ Number of rooms in dwelling } & 4 & $\geq 2$ rooms per person in household \\
\hline & 3 & $1-2$ rooms per person in household \\
\hline & 2 & $0.5-1$ rooms per person in household \\
\hline & 1 & $<0.5$ rooms per person in household \\
\hline \multirow[t]{4}{*}{ Household rating } & 4 & Money for extra things such as holidays and luxury goods \\
\hline & 3 & $\begin{array}{l}\text { Money for most of the important things but few } \\
\text { luxury goods }\end{array}$ \\
\hline & 2 & $\begin{array}{l}\text { Money for food and clothes, but short on many other } \\
\text { things }\end{array}$ \\
\hline & 1 & Not enough money for basic things like food and clothes \\
\hline \multirow[t]{4}{*}{ Drinking water source } & 4 & Piped water (tap) in dwelling \\
\hline & 3 & Piped water (tap) in site/yard \\
\hline & 2 & Public/communal tap \\
\hline & 1 & $\begin{array}{l}\text { Water carrier/tanker, rainwater tank, borehole/well/ } \\
\text { spring, dam/river/stream, or other }\end{array}$ \\
\hline
\end{tabular}


were unemployed. Most men reported that their main source of income was a formal salary (63.8\%), although a third of them reported that they had received no income in the past month (34.9\%). The vast majority of men had attended school at some point

Table 2. Social and demographic characteristics of key populations, SA 2012

\begin{tabular}{|c|c|c|c|c|}
\hline & \multicolumn{2}{|c|}{$\begin{array}{c}\text { Black men aged } \\
25-49 \text { years }\end{array}$} & \multicolumn{2}{|c|}{$\begin{array}{c}\text { Black women aged } \\
20 \text { - } 34 \text { years } \\
\end{array}$} \\
\hline & $n$ & Column \%* & $n$ & Column \%* \\
\hline \multicolumn{5}{|l|}{ Age (years) } \\
\hline $20-24$ & - & - & 1320 & 38.7 \\
\hline $25-29$ & 1028 & 30.3 & 1180 & 34.6 \\
\hline $30-34$ & 770 & 22.7 & 910 & 26.7 \\
\hline $35-39$ & 596 & 17.6 & - & - \\
\hline $40-44$ & 535 & 15.8 & - & - \\
\hline $45-49$ & 465 & 13.7 & - & - \\
\hline \multicolumn{5}{|l|}{ Locality type } \\
\hline Urban formal & 1412 & 41.6 & 1345 & 39.4 \\
\hline Urban informal & 719 & 21.2 & 636 & 18.7 \\
\hline Rural informal & 870 & 25.6 & 1147 & 33.6 \\
\hline Rural formal & 393 & 11.6 & 282 & 8.3 \\
\hline \multicolumn{5}{|l|}{ Employment status } \\
\hline Full-time employment & 1160 & 42.4 & 525 & 17.3 \\
\hline Part-time employment & 529 & 19.3 & 332 & 10.9 \\
\hline Student & 34 & 1.2 & 303 & 10.0 \\
\hline Unemployed & 840 & 30.7 & 1522 & 50.1 \\
\hline Homemaker/sick/disabled/other & 173 & 6.3 & 357 & 11.7 \\
\hline \multicolumn{5}{|l|}{ Main source of income in past month } \\
\hline Formal salary & 1033 & 63.8 & 536 & 39.0 \\
\hline Family contributions & 59 & 3.6 & 116 & 8.4 \\
\hline Grants/pensions & 115 & 7.1 & 435 & 31.7 \\
\hline Other & 412 & 25.4 & 286 & 20.8 \\
\hline \multicolumn{5}{|l|}{ Income in past month } \\
\hline No income & 928 & 34.9 & 1532 & 51.7 \\
\hline$<$ ZAR2 500 & 993 & 37.3 & 1136 & 38.3 \\
\hline$\geq$ ZAR2 500 & 741 & 27.8 & 296 & 10.0 \\
\hline Never attended school & 160 & 5.2 & 85 & 2.8 \\
\hline Ever attended school & 2899 & 94.8 & 2991 & 97.2 \\
\hline \multicolumn{5}{|l|}{ Highest education level } \\
\hline Primary & 737 & 24.3 & 356 & 11.5 \\
\hline Secondary & 2016 & 66.4 & 2475 & 80.2 \\
\hline Tertiary or higher & 283 & 9.3 & 256 & 8.3 \\
\hline \multicolumn{5}{|l|}{ Relationship to head of household } \\
\hline Head & 1606 & 48.1 & 459 & 13.7 \\
\hline Husband/wife/partner & 165 & 4.9 & 600 & 18.0 \\
\hline Son/daughter & 860 & 25.8 & 1267 & 37.9 \\
\hline Other & 705 & 21.1 & 1015 & 30.4 \\
\hline
\end{tabular}

in time $(94.8 \%)$, and $9.3 \%$ had received a tertiary education. Nearly half of the male respondents $(48.1 \%)$ reported being the head of their household.

Among black women aged 20 - 34 years, the largest unweighted proportion was

aged $20-24$ years (38.7\%). The greatest proportion of respondents were living in urban formal localities (39.4\%), and were unemployed (50.1\%). Only a minority (17.3\%) reported full-time employment. Less than half reported that their main source of income in the past month was from a formal salary $(39.0 \%)$, with nearly a third $(31.7 \%)$ reporting that their main source of income was grants or pensions. The majority of women $(51.7 \%)$ reported no income in the past month. Almost all women reported having some schooling (97.2\%), and 8.3\% had received tertiary education or higher. A minority of women reported being the head of their household (13.7\%), and the greatest proportion reported being the daughter of the head of household (37.9\%).

Table 3 shows the household characteristics of black men aged 25 - 49 years and black women aged 20 - 34 years. About half of men and women reported not having access to a flush toilet ( $45.5 \%$ and $50.2 \%$, respectively). A minority of participants reported using a cooking fuel besides electricity or gas ( $17.8 \%$ for men and $18.1 \%$ for women). The majority of men and women reported having household access to electricity and owning a radio, television, cell phone and refrigerator. A small proportion of individuals reported household access to a landline telephone (8.1\% for men and $8.7 \%$ for women), a personal computer $(16.6 \%$ for men and $15.8 \%$ for women) or a washing machine (26.7\% for men and $26.9 \%$ for women). A minority of participants reported living in one-room dwellings $(10.4 \%$ for men and $7.1 \%$ for women), while a higher proportion reported that they had only one room in the dwelling used for sleeping $(23.0 \%$ for men and $17.6 \%$ for women). Half of the respondents reported not having enough money for access to necessities such as food and clothing (52.9\% of men and $51.9 \%$ of women). A minority of respondents (11.0\% of men and $12.4 \%$ of women) reported using rainwater tanks, wells/springs and rivers/ streams as sources of drinking water.

The Cronbach's a for the SES scale was 0.82 . The median SES score for black women aged $20-34$ years was 36 (interquartile range (IQR) 31 - 41), and for black men aged 25 - 49 years the median was 36 (IQR 31 41). SES scores differed significantly by HIV status among 20 - 34-year-old black women (mean among positive 33.0, mean among negative $35.6 ; p<0.001)$ and among 25 49 -year-old men (mean among positive 33.3, mean among negative $34.8 ; p=0.002$ ).

Table 4 shows the associations of SES, age, behavioural risks and social factors with HIV status among black men aged $25-49$ 


\section{Table 3. Household characteristics of key populations, SA 2012}

\begin{tabular}{|c|c|c|c|c|}
\hline & \multicolumn{2}{|c|}{$\begin{array}{c}\text { Black men aged } \\
25-49 \text { years }\end{array}$} & \multicolumn{2}{|c|}{$\begin{array}{l}\text { Black women aged } \\
20 \text { - } 34 \text { years }\end{array}$} \\
\hline & $n$ & Column \%* & $n$ & Column \%* \\
\hline \multicolumn{5}{|l|}{ Toilet availability } \\
\hline No facility/other & 207 & 6.2 & 199 & 6.0 \\
\hline Pit latrine without ventilation/bucket latrine & 812 & 24.4 & 887 & 26.7 \\
\hline Pit latrine with ventilation & 497 & 14.9 & 585 & 17.6 \\
\hline Flush toilet (own or shared) & 1813 & 54.5 & 1656 & 49.8 \\
\hline \multicolumn{5}{|l|}{ Cooking fuel } \\
\hline Wood, dung, or other & 291 & 8.9 & 356 & 10.9 \\
\hline Paraffin (kerosene) & 234 & 7.2 & 186 & 5.7 \\
\hline Coal & 54 & 1.7 & 48 & 1.5 \\
\hline Electricity or gas & 2679 & 82.2 & 2676 & 81.9 \\
\hline \multicolumn{5}{|l|}{ Household access to } \\
\hline Electricity & 2841 & 85.3 & 2885 & 86.7 \\
\hline Radio & 2490 & 75.4 & 2459 & 74.2 \\
\hline Television & 2546 & 76.9 & 2655 & 80.0 \\
\hline Landline telephone & 265 & 8.1 & 285 & 8.7 \\
\hline Cell phone & 3028 & 91.8 & 3089 & 93.7 \\
\hline Refrigerator & 2351 & 70.9 & 2499 & 75.6 \\
\hline Personal computer & 547 & 16.6 & 522 & 15.8 \\
\hline Washing machine & 882 & 26.7 & 891 & 26.9 \\
\hline \multicolumn{5}{|l|}{ Number of rooms in dwelling } \\
\hline 1 & 345 & 10.4 & 238 & 7.1 \\
\hline $2-3$ & 854 & 25.6 & 772 & 23.2 \\
\hline $4-5$ & 1221 & 36.7 & 1288 & 38.6 \\
\hline$\geq 6$ & 910 & 27.3 & 1036 & 31.1 \\
\hline \multicolumn{5}{|l|}{ Number of rooms for sleeping } \\
\hline 1 & 764 & 23.0 & 587 & 17.6 \\
\hline 2 & 1133 & 34.1 & 1147 & 34.5 \\
\hline$\geq 3$ & 1425 & 42.9 & 1595 & 47.9 \\
\hline \multicolumn{5}{|l|}{ Household situation description } \\
\hline $\begin{array}{l}\text { Not enough money for basic things like food } \\
\text { and clothes }\end{array}$ & 1553 & 52.9 & 1549 & 51.9 \\
\hline $\begin{array}{l}\text { Money for food and clothes, but short on } \\
\text { many other things }\end{array}$ & 1007 & 34.3 & 1080 & 36.2 \\
\hline $\begin{array}{l}\text { We have most of the important things, but } \\
\text { few luxury goods }\end{array}$ & 320 & 10.9 & 295 & 9.9 \\
\hline $\begin{array}{l}\text { Money for extra things such as holidays and } \\
\text { luxury goods }\end{array}$ & 57 & 1.9 & 61 & 2.0 \\
\hline \multicolumn{5}{|l|}{ Main source of drinking water } \\
\hline Piped water (tap) in dwelling & 1427 & 44.4 & 1393 & 43.9 \\
\hline Piped water (tap) in site/yard & 1008 & 31.3 & 952 & 30.0 \\
\hline Public/communal tap & 429 & 13.3 & 436 & 13.7 \\
\hline Other & 353 & 11.0 & 392 & 12.4 \\
\hline
\end{tabular}

years. In bivariate analyses, the SES scale, age, condom use at last sexual encouter, and self-perception of HIV risk were statistically significantly associated with HIV status among black men. In adjusted analyses, SES scale was only weakly $(p=0.097)$ inversely associated with HIV status among men, with a one-point increase in the SES scale (higher SES) being associated with a small decrease (1.7\%) in adjusted odds of being HIV-positive. Condom use at last sexual encouter and self-perception of HIV risk were both strongly positively associated with HIV status among black men.

Table 5 shows the associations with HIV status among black women aged 20 - 34 years. In bivariate analyses, SES, age, locality type, condom use at last sexual encounter, lifetime number of sexual partners and selfperception of HIV risk were all statistically significantly associated with HIV status. In the multiple logistic regression analysis, a statistically significant strong inverse relationship was found between SES and HIV status $(p<0.001)$. Each one-point increase in the SES scale (higher SES) was associated with a $3.9 \%$ (95\% confidence interval 2.2 5.6) decrease in adjusted odds of being HIVpositive among black women. Women who were older ( 25 - 34 years), reported using a condom at last sexual encounter, reported more than one lifetime sexual partner, and perceived themselves to be at risk for HIV were more likely to be HIV-positive.

\section{Discussion}

In contemporary SA, racial inequalities remain interwoven with economic inequality, and wealth continues to reflect apartheid hierarchies, with whites at the top of the pyramid and black Africans at the bottom. ${ }^{[7]}$ The HIV epidemic has developed in this inequitable social context and has thrived among black communities, especially in overcrowded, poor urban areas where there are poor sanitation and living conditions and the basic necessities of life are scarce. ${ }^{[8]}$ A series of national surveys have shown that HIV affects black Africans disproportionately, ${ }^{[1,2]}$ with no respite apparent. The goal of this article is to move beyond generalisations at the population level and instead present a deeper understanding of the epidemic by focusing on two subpopulations most affected by HIV. The findings presented in the report published earlier ${ }^{[2]}$ suggested that the epidemic is concentrated among black African women aged 20-34 years and men aged 25 - 49 years. These two groups, accounting for the majority of the country's HIV-positive population (57.3\%) and nearly half of the newly infected population (48\%) in 2012, constitute additional key populations for HIV risk. If they are not the main target of HIV prevention programmes, SA is unlikely to significantly reduce new infections in the 
Table 4. Associations with HIV status among black men aged 25 - 49 years, SA 2012

\begin{tabular}{|c|c|c|c|c|}
\hline & OR & 95\% CI & $\mathrm{aOR}$ & 95\% CI \\
\hline SES scale & $0.98^{\ddagger}$ & $0.96-0.99$ & $0.98^{*}$ & $0.96-1.00$ \\
\hline \multicolumn{5}{|l|}{ Age (years) } \\
\hline $25-29$ & Ref & Ref & Ref & Ref \\
\hline $30-34$ & $1.59^{\ddagger}$ & $1.20-2.10$ & 1.32 & $0.91-1.92$ \\
\hline $35-39$ & $1.75^{\ddagger}$ & $1.30-2.34$ & 1.36 & $0.92-2.03$ \\
\hline $40-44$ & $1.31^{*}$ & $0.95-1.79$ & 0.99 & $0.63-1.53$ \\
\hline $45-49$ & 1.03 & $0.73-1.47$ & 1.10 & $0.69-1.76$ \\
\hline \multicolumn{5}{|l|}{ Locality type } \\
\hline Urban formal & Ref & Ref & Ref & Ref \\
\hline Urban informal & 1.23 & $0.94-1.61$ & 1.17 & $0.78-1.74$ \\
\hline Rural informal & 1.06 & $0.82-1.36$ & 0.99 & $0.68-1.44$ \\
\hline Rural formal & 1.21 & $0.89-1.63$ & 1.22 & $0.77-1.93$ \\
\hline Condom use at last sex & $1.77^{\ddagger}$ & $1.41-2.21$ & $1.69^{\ddagger}$ & $1.28-2.23$ \\
\hline \multicolumn{5}{|l|}{ Lifetime number of sex partners } \\
\hline 1 & Ref & Ref & Ref & Ref \\
\hline $2-3$ & 1.33 & $0.86-2.04$ & 1.04 & $0.56-1.95$ \\
\hline $4-5$ & 1.40 & $0.91-2.16$ & 1.06 & $0.57-1.98$ \\
\hline$\geq 6$ & 1.42 & $0.93-2.15$ & 1.16 & $0.63-2.13$ \\
\hline Self-perceived to be at risk for HIV & $2.26^{\ddagger}$ & $1.84-2.78$ & $2.11^{\ddagger}$ & $1.59-2.80$ \\
\hline
\end{tabular}

Table 5. Associations with HIV status among black women aged 20 - 34 years, SA 2012

\begin{tabular}{|c|c|c|c|c|}
\hline & OR & 95\% CI & $\mathrm{aOR}$ & 95\% CI \\
\hline SES scale & $0.96^{*}$ & $0.95-0.972$ & $0.96^{*}$ & $0.94-0.98$ \\
\hline \multicolumn{5}{|l|}{ Age (years) } \\
\hline $20-24$ & Ref & Ref & Ref & Ref \\
\hline $25-29$ & $1.98^{*}$ & $1.61-2.44$ & $1.66^{\star}$ & $1.25-2.20$ \\
\hline $30-34$ & $3.06^{*}$ & $2.46-3.79$ & $2.32^{*}$ & $1.71-3.14$ \\
\hline \multicolumn{5}{|l|}{ Locality type } \\
\hline Urban formal & Ref & Ref & Ref & Ref \\
\hline Urban informal & $1.74^{*}$ & $1.37-2.21$ & 1.26 & $0.88-1.81$ \\
\hline Rural informal & $1.42^{\star}$ & $1.15-1.73$ & 1.30 & $0.95-1.77$ \\
\hline Rural formal & $1.85^{\star}$ & $1.38-2.50$ & 1.13 & $0.72-1.78$ \\
\hline Condom use at last sex & $1.53^{*}$ & $1.26-1.84$ & $1.98^{*}$ & $1.56-2.52$ \\
\hline \multicolumn{5}{|l|}{ Lifetime number of sex partners } \\
\hline 1 & Ref & Ref & Ref & Ref \\
\hline $2-3$ & $1.99^{*}$ & $1.58-2.51$ & $2.25^{*}$ & $1.63-3.10$ \\
\hline $4-5$ & $2.67^{*}$ & $2.02-3.52$ & $2.71^{*}$ & $1.84-4.00$ \\
\hline$\geq 6$ & $2.76^{*}$ & $1.96-3.88$ & $2.67^{*}$ & $1.66-4.31$ \\
\hline Self-perceived to be at risk for HIV & $2.42^{*}$ & $2.04-2.88$ & $2.07^{*}$ & $1.63-2.63$ \\
\hline
\end{tabular}

coming years. It is important to understand the demographic characteristics of these groups and the social determinants associated with their increased HIV risk.
The results presented add to the body of knowledge suggesting that SES and specifically inequality (both social and income) are important social determinants for HIV risk and infections, particularly among women. SES not only reflects social standing of an individual or group, but also denotes social class, privilege, power and control. The findings suggest that social determinants such as social inequality, income inequality and lack of economic opportunities are associated with being HIVpositive in the two key populations studied, with a much stronger effect observed among black women aged 20 - 34 years. Evidence shows that HIV is a disease that is associated with social and economic inequity and poverty. ${ }^{[9,10]}$ High rates of unemployment in SA can be understood as a significant factor driving the HIV epidemic, ${ }^{[1]}$ and empirical evidence has pointed to increased educational attainment as a method of lowering the incidence. ${ }^{[12]}$

The subject of race and HIV, and who is susceptible to HIV and why, remains a sensitive and controversial issue. Researchers have focused on sociocultural and behavioural aspects in explaining the observed HIV disparities by race. ${ }^{[10]}$ However, data from the USA are beginning to challenge some of these assumptions by showing that it is the individual's socioeconomic environment ('place'), rather than race alone, which may influence behaviour that increases or decreases the likelihood of contracting HIV ${ }^{[10]}$

In a country like SA, with a history of racial segregation and race-based oppression, race should be understood as a determinant of one's SES, and it is SES coupled with other factors that protects one from or puts one at risk of HIV. Research has shown a strong association between HIV, SES, race and locality ${ }^{[1,2]}$ Income and social inequality in particular are emerging as important social determinants for predicting not only risk behaviour but also HIV prevalence and incidence among black South Africans. This is also the case among black Americans in the USA. ${ }^{[10]}$ In the current article, an analysis of socioeconomic factors showed that the two groups (black African women aged 20 - 34 years and men aged 25 - 49 years) are likely to fall into the lower SES rungs and face significant challenges with regard to accessing formal employment, income, education (especially higher education), formal housing, and basic household services and items.

Poverty is understood to be a driving force behind the HIV/AIDS epidemic in subSaharan Africa as both a cause and effect of the disease, ${ }^{[9]}$ and empirical research has pointed to an association between HIV prevalence and lower SES. ${ }^{[13,14]}$ Women globally, and black African women in particular, tend to fall into the lower socioeconomic stratum 
and are disproportionately affected by HIV. ${ }^{[15]}$ There is also evidence that the association between HIV, SES and gender varies depending on income inequality in the general population. Where income per capita is high and intracountry inequalities are high, HIV risk increases. ${ }^{[14]}$

With regard to employment status, black women were more likely than black men to be unemployed and looking for work. Full-time employment rates were higher for men than for women. An analysis by income showed that black men were more likely to have a formal source of income, while women were more likely to have no income and tended to be dependent on welfare, namely grants and charity. While the study found that both genders are disadvantaged, black women were found to be more socioeconomically disadvantaged than their male counterparts. Among women, lower social standing and the experience of life stress have been associated with risky sexual practices such as transactional sex and lack of consistent condom use. Access to resources and power determines vulnerability to diseases and poor health outcomes. Poor access to or lack of socioeconomic resources can lead to riskier health behaviours, as individuals belonging to groups with lower SES may not always have access to resources or interventions that they can use to protect themselves.

There is evidence to suggest that race or ethnicity and social class are critical factors in the increased risk of HIV. SES determines where one lives and the conditions to which one is exposed. Residential settlements in SA remain segregated by race and SES. The link between locality and HIV is poorly understood; however, evidence from the USA suggests that residential segregation, which is characterised by white-black dissimilarity, and black isolation, is a very strong predictor of HIV incidence among blacks. ${ }^{[10]}$ This has led to some researchers arguing that institutional and structural racism is a neglected factor contributing to HIV infection among blacks. ${ }^{[10]}$

The findings presented in this article are in line with a study of 80 cities in the USA that found that income inequality, poverty, and racial segregation of black individuals was a significant predictor of HIV incidence. It was further observed that high income inequality, low incomes, high unemployment, high poverty, low home ownership and a high cost of living correlated positively with HIV incidence. ${ }^{[10]}$ With regard to access to formal income, employment and education, the results of this article suggest that HIV-positive men and HIV-positive women were in a worse position than their male and female counterparts who were HIV-negative. The analysis by gender shows that increases in SES had a stronger protective effect against HIV for black women.

Among both key populations analysed, condom use at last sexual encounter and self-perceived HIV risk were statistically significantly associated with HIV status. Additionally, among 20 - 34-year-old black women, older age and multiple lifetime sexual partners were statistically significantly associated with HIV status. These predictors are investigated in greater detail in the study report. ${ }^{[2]}$

It should be noted that black Africans had the highest HIV testing response rate in the survey, $73.3 \%$ as opposed to $67.5 \%$ in the total population. A detailed analysis comparing HIV risk-related characteristics among survey respondents who were interviewed and tested with those who were interviewed but refused HIV testing found no evidence that the HIV survey results were biased as a result of HIV testing refusal. ${ }^{[2]}$

Owing to the limitations of a cross-sectional study, it was not possible to determine the causal sequence between HIV infection and SES; as previously stated, low SES has been understood as both a cause and effect of the HIV epidemic in sub-Saharan Africa. Existing research suggests that HIV status often has a negative impact on SES by limiting the individual's ability to work and earn income. ${ }^{[16]}$ For those who are already positive, being poor and unemployed may also create challenges to accessing healthy food and antiretroviral treatment, leading to a faster progression from HIV to AIDS. Positive HIV status may further entrench a cycle of social and income inequality that leads to poverty. ${ }^{[9]}$

\section{Conclusion}

It is not surprising that low SES appears to be a risk factor for HIV infection, especially for the key population of black African women aged 20 - 34 years, with marginal significance for black African men aged 25 - 49 years, as socioeconomic and racial inequalities have a direct impact on these populations. Gender inequality further disadvantages black African women. Additional research is necessary to expand understanding of these additional key populations and determine the social and structural characteristics that increase their risks of HIV infection.

Although biomedical prevention and behaviour change interventions are critical for combating the HIV epidemic in SA, it is equally important that energy is directed towards shifting the core structural drivers of HIV, namely economic, racial, and gender inequalities. Targeted interventions for black African key populations should prioritise socioeconomic empowerment, access to formal housing and services, and access to higher education, especially for women. Access to antiretroviral therapy and health services for these communities also needs to be scaled up, and racial disparities in access and quality addressed. The government's decision to move towards universal healthcare should be lauded; however, implementation remains a pressing challenge. Policy shifts should support the goal of economic transformation and the redistribution of wealth to address racial disparities.

Acknowledgements. This article was supported by the President's Emergency Plan for AIDS Relief (PEPFAR) through the CDC under the terms of $3 \mathrm{U} 2 \mathrm{GGH} 000570$. Its contents are solely the responsibility of the authors and do not necessarily represent the official views of the CDC. The Johns Hopkins University Center for AIDS Research (1P30AI094189) and the National Institutes of Health (T32AI102623) are also acknowledged.

\section{References}

1. Shisana O, Rehle T, Simbayi LC, et al. South African National HIV Prevalence, Incidence, Behaviour and Communication Survey, 2008: A Turning Tide Among Teenagers? Cape Town: HSRC Press, 2009. and Communication Survey, 2008: A Turning Tide Among Teenagers? Cape Town: HSRC Press, 2009. Survey, 2012. Cape Town: HSRC Press, 2014.

3. Beyrer C, Baral S, Kerrigan D, et al. Expanding the space: Inclusion of most-at-risk populations in HIV 3. Beyrer C, Baral S, Kerrigan D, et al. Expanding the space: Inclusion of most-at-risk populations in HIV
prevention, treatment, and care services. J Acquir Immune Defic Syndr 2011;57(Suppl 2):S96-S99. [http://dx.doi.org/10.1097/QAI.0b013e31821db944]

4. Baral SD, Poteat T, Strömdahl S, et al. Worldwide burden of HIV in transgender women: A systematic review and meta-analysis. Lancet Infect Dis 2013;13(3):214-222. [http://dx.doi.org/10.1016/S14733099(12)70315-8]

5. Rispel LC, Metcalf CA, Cloete A, et al. HIV prevalence and risk practices among men who have sex with men in two South African cities. J Aquir Immune Defic Syndr 2011;57(1):69-76. [http://dx.doi. org/10.1097/QAI.0b013e318211b40a

6. UNAIDS. UNAIDS Guidance for Partnerships with Civil Society Including People Living with HIV and Key Populations. Geneva: Joint United Nations Programme on HIV/AIDS, 2012.

. Statistics South Africa. Census 2011. Pretoria: Statistics South Africa, 2012.

8. Mayosi BM, Lawn JE, van Niekerk A, et al. Health in South Africa: Changes and challenges since 2009. . Mayosi BM, Lawn JE, van Niekerk A, et al. Health in South Africa: Changes and challengs
Lancet 2012;380(9858):2029-2043. [http://dx.doi.org/10.1016/S0140-6736(12)61814-5]

Lancet 2012;380(9858):2029-2043. [http://dx.doi.org/10.1016/S0140-6736(12)61814-5]
9. Shisana O Zungu N, Pezi S. Poverty and HIV and AIDS. In: Rohleder P, Cameron E, Swartz L, et al., eds. 9. Shisana O, Zungu N, Pezi S. Poverty and HIV and AIDS. In: Rohleder P, Ca
HIV/AIDS in South Africa 25 Years On. New York: Springer, 2009:89-104.

HIV/AIDS in South Africa 25 Years On. New York: Springer, 2009:89-104.
10. Buot MLG, Docena JP, Ratemo BK, et al. Beyond race and place: Distal sociological determinants of HIV disparities. PLoS One 2014;9(4):e91711. [http://dx.doi.org/10.1371/journal.pone.0091711]

11. Hunter M. The changing political economy of sex in South Africa: The significance of unemployment and inequalities to the scale of the AIDS pandemic. Soc Sci Med 2007;64(3):689-700. [http://dx.doi. org/10.1016/j.socscimed.2006.09.015

12. Bärnighausen T, Hosegood V, Timaeus IM, Newell ML. The socioeconomic determinants of HIV incidence: Evidence from a longitudinal, population-based study in rural South Africa. AIDS 2007;21(Suppl 7):S29-S38. [http://dx.doi.org/10.1097/01.aids.0000300533.59483.95]

13. Buve A, Bishikwabo-Nsarhaza K, Mutangadura G. The spread and effect of HIV-1 infection in subSaharan Africa. Lancet 2002;359(9322):2011-2017. [http://dx.doi.org/10.1016/S0140-6736(02)08823-2] Wojcicki IM. Socioeconomic status as a risk factor for HIV infection in women in East Central and Southern Africa: A systematic review. J Biosoc Sci 2005;37(1):1-36. [http://dx.doi.org/10.1017/
and

5. UNAIDS. Global Report: UNAIDS Report on the Global HIV Epidemic 2013. Geneva: Joint United N. UNAIDS. Global Report: UNAIDS Report
Nations Programme on HIV/AIDS, 2013.

Nations Programme on HIV/AIDS, 2013 .
6abkin JG, McElhiney M, Ferrando SJ, et al. Predictors of employment of men with HIV/AIDS: A longitudinal study. Psychosom Med 2004;66(1):72-78.

Accepted 15 June 2015. 